\title{
Investigating the Effect of High Pressures and Temperatures on Corrosion Inhibition for Water-Based Drilling Fluids
}

\author{
Mahmood Amani*, Abdul Salam Abd, Abdulrahman Al-Hardan, Alireza Roustazadeh, Rommel Yrac \\ Texas A\&M University, Qatar
}

\begin{abstract}
Corrosion is defined as the gradual degradation of materials as a result of reaction with their environment. In gas and oil sector and during the well life, equipment can corrode at any stage causing enormous losses in time and money. Inhibiting corrosion while drilling is considered to be one of the best solutions for corrosion, as chemical inhibition can be acquainted with the drilling fluid itself. The purpose of this paper is to study the effects of corrosion of steel pipes of different sizes (3.5', 4.5' and 5.5') and discuss the possible inhibition treatments.

In the lab, the change in thickness as well as weight was recorded. Then, the material properties were compared under the effect of diverse corrosion media conditions (temperature, base fluid, inhibitive fluid). Each sample was exposed to about 100 hours of corrosion. The final results showed that corrosion rate is the highest when only water based mud is present in the medium. However, corrosion rate is less severe under ambient temperature conditions contrary to High Pressure High Temperature (HPHT) medium were corrosion rate was severe (around $4.1 \mathrm{lbs} / \mathrm{ft}^{\wedge} 2-$ year). It was also noted that the corrosion rate is inversely proportional to pipe thickness: as the diameter increases, the corrosion rate decreases accordingly.

When inhibitor (Conqor 404) is presented, it was observed that the rate of corrosion decreased drastically in the HPHT medium. Here, another relation can be established: as more inhibitor is injected into the mud, the corrosion rate reaches an economic margin where high concentration of the inhibitor is not feasible anymore.

Introducing inhibitor (OSL 1) to the mud instead of (Concor 404) will cause the corrosion rate to decrease to a low state, but higher than the rate achieved while using Concor 404 in same concentration. Mixing both inhibitors (OSL 1 + Concor 404) together will yield inhibition results better than using OSL 1 alone. Although Concor 404 was proven to be the best inhibitor when presented in considerably high concertation, it is recommended to use a combination of Concor 404 and OSL 1 as it has desirable results under HPHT conditions with feasible cost. The final decision depends merely on the metal type and limiting corrosion rate for that specific metal.
\end{abstract}

Keywords: Drilling; Corrosion; Degradation; Inhibitor; Efficiency

\section{Introduction}

Corrosion is defined as gradual degradation of metal caused by a chemical or electrochemical reaction with its environment. In oil and gas sector, components can corrode at any stage in the life of a field starting from drilling through to abandonment. Recent estimations showed that corrosion costs the oil industry in US yearly around $\$ 170$ billion. In general, $50 \%$ of the operating expenditures in the drilling sector worldwide are for taming corrosion in drill pipe and down-hole equipment. On the other hand, "a corrosion inhibitor is a substance when added in a small concentration to an environment reduces the corrosion rate of a metal exposed to that environment. Inhibitors often play an important role in the oil extraction and processing industries where they have always been considered to be the first line of defence against corrosion" (SLB Glossary). Since the corrosion process is mostly due to the chemical reactions on the surface of the metal under HPHT condition, water-based mud properties used are hence of great effect. Mitigating corrosion is a very serious challenge for the oil and gas industry as it can't be totally eliminated. Because it is almost impossible to prevent corrosion, it is becoming more apparent that controlling the corrosion rate may be the most economical solution. Thus, the first step to tackle this problem is by determining the cause of the corrosion itself. This is vital as it helps understand the mechanism and the process behind corrosion to suggest more practical and helpful solutions. Nowadays, the urge to drill deeper to recover larger amounts of hydrocarbons exposes the drillers to High pressure/High Temperature (HPHT) zones. Wells with temperatures greater than $300 \mathrm{~F}$ and pressures of 1000 psig are classified as HPHT wells [1]. Moreover, using water based muds (WBM's) will increase the likelihood of a severe corrosion to happen under HPHT conditions.

\section{Significance}

This research is vital to the oil industry as it discusses a problem that has been ongoing for a long time. Corrosion is causing the oil companies a tremendous economic loss. In some cases, and in order to continue the drilling process, the tubing should be changed completely. There have been a lot of experiments on how to mitigate corrosion; however, the success rates are still low. Corrosion cannot be inhibited completely; however, the aim is to control it. Adding special additives to the drilling fluid or coating the tube with certain chemical are some ways to stop corrosion [2]. The aim of this research is to subject various metal samples of different grades to stress and strain similar to those caused by severe HPHT condition downhole, and compare the results of two main categories: treated samples and untreated samples.

"Corresponding author: Amani M, Texas A\&M University, Qatar, Tel: +974-4423-0119 E-mail: mahmood.amani@qatar.tamu.edu

Received August 24, 2016; Accepted September 03, 2016; Published September 10, 2016

Citation: Amani M, Abd AS, Al-Hardan A, Roustazadeh A, Yrac R, et al. (2016) Investigating the Effect of High Pressures and Temperatures on Corrosion Inhibition for Water-Based Drilling Fluids. J Pet Environ Biotechnol 7: 297. doi: 10.4172/2157-7463.1000297

Copyright: @ 2016 Amani M, et al. This is an open-access article distributed under the terms of the Creative Commons Attribution License, which permits unrestricted use, distribution, and reproduction in any medium, provided the original author and source are credited. 
Citation: Amani M, Abd AS, Al-Hardan A, Roustazadeh A, Yrac R, et al. (2016) Investigating the Effect of High Pressures and Temperatures on Corrosion Inhibition for Water-Based Drilling Fluids. J Pet Environ Biotechnol 7: 297. doi: 10.4172/2157-7463.1000297

The metals are expected to handle more stress when treatment is applied, proving the efficiency of the corrosion inhibitors compared to untreated samples. The challenge is to be able to manufacture an inhibitive chemical that can provide long term resistance as well as durable adherence on the steel [3].

\section{Methodology}

Corrosion needs 4 main elements to happen: anode, cathode, electrolyte (fluid) and external connection. In case any of these elements is absent, corrosion will not take place [4]. In our research, water based mud is the electrolyte of interest. In general, water helps in speeding the corrosion of metal where the steel itself serves as the external connection. The rate of corrosion depends purely on the grade of the metal and the generated potential due the dry cell effect. Oxygen $\left(\mathrm{O}_{2}\right)$ which plays an important role in corrosion is only present at the drilling stage and not in the producing formations. Water and Carbon dioxide $\left(\mathrm{CO}_{2}\right)$ injected at recovery operation can cause severe corrosion of completion string. Also, the presence of hydrogen sulfide $\left(\mathrm{H}_{2} \mathrm{~S}\right)$ gases at HPHT has a major role in the dynamics of corrosion. Thus, finding the effect of those elements $\left(\mathrm{O}_{2}, \mathrm{CO}_{2}\right.$ and $\left.\mathrm{H}_{2} \mathrm{~S}\right)$ in the corrosion process is very important to understand corrosion process.

First, the most common element that interfere in the corrosion process is the dissolved oxygen. The reaction of the iron to the oxygen contained in water will form iron rust (Figure 1). The equation below shows the reaction governing the process:

$$
2 \mathrm{Fe}^{++}+1 / 2 \mathrm{O}_{2}+\mathrm{H}_{2} \mathrm{O}=2 \mathrm{Fe}^{+++}+2 \mathrm{OH}^{-}
$$

The formed rust is called ferric hydroxide which is characterized as insoluble.

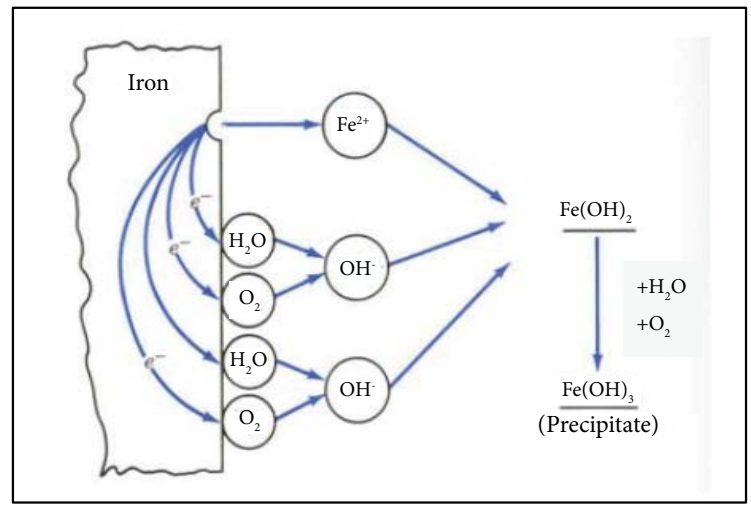

Figure 1: Formation of rust due to corrosion of steel

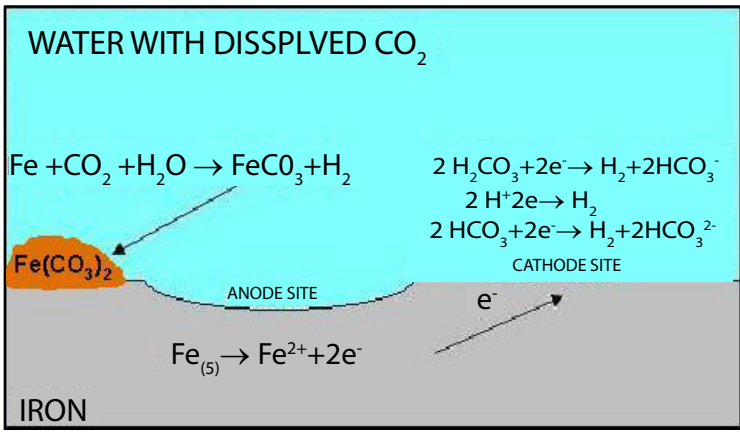

Figure 2: Formation of bicarbonate due to iron corrosion.
While drilling, we will have infinite oxygen as it is an open system operation, thus the corrosion will not cease. The corrosion rate is usually higher when the concentration of oxygen is low thus leading to rust that is impermeable to $\mathrm{O}_{2}$ diffusion compared to that at high $\mathrm{O}_{2}$ concentrations.

Second, the presence of dissolved $\mathrm{CO}_{2}$ in water causes the steel to corrode where the rate of corrosion depends mainly on the quantity of $\mathrm{CO}_{2}$ and $\mathrm{O}_{2}$ present as well as temperature and composition of the material. This reaction is weaker than that induced by the presence of $\mathrm{O}_{2}$ for equal quantities. In $\mathrm{CO}_{2}$ based corrosion, carbon dioxide reacts with water to form bicarbonate (Figure 2). The following equation governs the reaction:

$$
2 \mathrm{CO}_{2}+2 \mathrm{H}_{2} \mathrm{O}+2 \mathrm{e}-=2 \mathrm{HCO}^{-3}+\mathrm{H}_{2}
$$

This equation indicates that the $\mathrm{CO}_{2}$, upon dissolving in water, acts like an acid. Thus, if we have dissolved $\mathrm{CO}_{2}$ and $\mathrm{O}_{2}$ combined in water, stronger corrosion rates will be observed.

Third, dissolved $\mathrm{H}_{2} \mathrm{~S}$ can be corrosive if dampness is present. The fact that $\mathrm{H}_{2} \mathrm{~S}$ is highly soluble in water creates a weak dibasic acid, which causes the degradation of iron because of the presence of oxygen. The reaction will be as follows:

$$
\mathrm{H}_{2} \mathrm{~S}+1 / 2 \mathrm{O}_{2}=\mathrm{H}_{2} \mathrm{O}+2 \mathrm{~S}
$$

The rate of corrosion is controlled by the concentration of the dissolved gas. If the dissolved $\mathrm{H}_{2} \mathrm{~S}$ is present in low quantities the corrosion will be severe. However, if the concentration of the dissolved $\mathrm{H}_{2} \mathrm{~S}$ is very, it might have reverse effect where it will act to inhibit the corrosion reaction.

When both $\mathrm{CO}_{2}$ and $\mathrm{H}_{2} \mathrm{~S}$ are present, while having direct contact with $\mathrm{O}_{2}$, there will create severe localized corrosion damage causing the material to crack and fail [5].

To go further with the influence of external factors on corrosion rate, we should consider the temperature of the medium. We should not only consider the fact that the reaction rate will increase simultaneously with temperature, but we should account for solubility and viscosity. The solubility of gases in water will decrease with temperature increase as well as the viscosity. However, this is scenario is not true in all cases. For example, when dissolved oxygen is present, the corrosion rate will increase with temperature till a critical point then it will start decreasing with oxygen solubility. If the system is open, the oxygen will escape. Otherwise, the oxygen will be trapped causing the rate of corrosion to increase at high temperatures.

As a result of corrosion, weight is expected to decrease and the weight loss is estimated according to the following equation:

$$
\Delta \mathrm{m}=\mathrm{W}_{\text {initial }}-\mathrm{W}_{\text {finial }}
$$

Where $\mathrm{W}_{\text {initial }}$ and $\mathrm{W}_{\text {final }}$ are the weight of each sample before and after corrosion in grams respectively

This allows for the estimation of a parameter: the corrosion rate according to equation (5) presented below:

$$
\mathrm{CR}=\frac{\Delta m}{\Delta t} \text { (grams/day) }
$$

Where $\Delta t$ is the time of the corrosion process in days.

The inhibitor efficiency is then estimated using the equation presented in the following:

Inhibitor Efficiency $=\frac{C R \text { uinhibited-CRinhibited }}{\text { CRuninhibited }} \times 100$ 
Citation: Amani M, Abd AS, Al-Hardan A, Roustazadeh A, Yrac R, et al. (2016) Investigating the Effect of High Pressures and Temperatures on Corrosion Inhibition for Water-Based Drilling Fluids. J Pet Environ Biotechnol 7: 297. doi: 10.4172/2157-7463.1000297

Page 3 of 5

\section{Equipment and materials used}

The equipment used in the experiments are:

a. $\quad(20 \mathrm{x}) 500 \mathrm{~mL}$ plastic bottles

b. Weight balance $(1 / 1000$ g accuracy)

c. Plastic Trays

d. OFITE HTHP fluid loss double end- cap

e. Conducting wires

f. Steel modified-stem

g. Heating jacket

The materials used in the experiment are:

a. (1x) Corrosion rings of size 3.5”

b. $\quad 0.5 \%, 1 \%, 1.5 \%$ HCL solution

c. (1x) Corrosion rings of size 4.5

d. $\quad 0.5 \%, 1 \%, 1.5 \%$ Concor 404 solution

e. $\quad(3 \mathrm{x})$ Corrosion rings of size 5.5

f. $\quad 0.5 \%, 1 \%, 1.5 \%$ OS1-L solution

g. Laboratory formulated Water Based Mud

\section{Preliminary Procedure (Pre-experimentation)}

\section{Safety measurements}

This experiment requires direct contact with synthetic chemicals which can hurt whoever is utilizing it. Inspecting the material safety data sheet (MSDS) of the chemicals utilized in this research is required. The MSDSs proved all the vital information on how to deal with the chemicals and how to act upon being exposed to those solutions. The MSDSs for the chemicals that will be used in this research will be provided in the Appendix [6].

\section{Phase 1}

Solution preparation: In the laboratory, a drilling water based fluid was prepared using mainly Drill water, Barite and Bentonite. Other additives such as $\mathrm{NaCl}$, Flowzan, Soda Ash and Fine $\mathrm{CaCO}_{3}$ were used as well. The properties of the formulated mud are summarized in Table 1 below. Different corroding solutions with varying composition were prepared and stored in plastic vessels as shown in Table 2.

Material preparation: The samples were prepared specific for each medium. The 3 corrosion rings were cut into 4 pieces in Texas A\&M University - Qatar machine shop. The initial weight of each sample was

\begin{tabular}{|c|c|}
\hline Rheology Temperature & $120^{\circ} \mathrm{F}$ \\
\hline Gel at 10 seconds & $14 \mathrm{lbs} / 100 \mathrm{sq} \mathrm{ft}$ \\
\hline Plastic Viscosity (PV) & $24 \mathrm{cP}$ \\
\hline Yield Point (YP) & $30 \mathrm{lbs} / 100 \mathrm{sq} \mathrm{ft}$ \\
\hline YP/PV Ratio & 1.25 \\
\hline Funnel Viscosity & $59 \mathrm{sec} / \mathrm{qt}$ \\
\hline HTHP & $100 \mathrm{psi} / 30 \mathrm{minutes}$ \\
\hline API Fluid Loss & $8 \%$ \\
\hline Low gravity solids & $12.00 \mathrm{ppg}$ \\
\hline Mud Weight & 9.8 \\
\hline pH & $200 \mathrm{mg} / \mathrm{L}$ \\
\hline Chlorides & $\mathrm{psi}$ Differential Pressure \\
\hline Table $1: \operatorname{lital} ~$ & $\mathrm{pr}$ \\
\hline
\end{tabular}

Table 1: Initial test results for the water base mud properties.

\begin{tabular}{|c|c|c|c|}
\hline Medium & Inhibitor Type & $\begin{array}{c}\text { Inhibitor } \\
\text { Concentration }\end{array}$ & Temperature \\
\hline 1 & None - base fluid & - & Ambient \\
\hline 2 & None - base fluid & - & Ambient \\
\hline 3 & None - base fluid & - & Ambient \\
\hline 4 & None - base fluid & - & HPHT $-230^{\circ} \mathrm{F}$ \\
\hline 5 & None - base fluid & - & HPHT $-230^{\circ} \mathrm{F}$ \\
\hline 6 & None - base fluid & - & HPHT $-230^{\circ} \mathrm{F}$ \\
\hline
\end{tabular}

Table 2: Different medium used in the reserach set-up for phase 1.

\begin{tabular}{|c|c|c|c|}
\hline Medium & Inhibitor Type & $\begin{array}{c}\text { Inhibitor } \\
\text { Concentration }\end{array}$ & Temperature \\
\hline 1 & Concor 404 & 0.5 & HPHT $-230^{\circ} \mathrm{F}$ \\
\hline 2 & Concor 404 & 1 & HPHT $-230^{\circ} \mathrm{F}$ \\
\hline 3 & Concor 404 & 1.5 & HPHT $-230^{\circ} \mathrm{F}$ \\
\hline 4 & OS1-L & 0.5 & HPHT $-230^{\circ} \mathrm{F}$ \\
\hline 5 & OS1-L & 1 & HPHT $-230^{\circ} \mathrm{F}$ \\
\hline 6 & OS1-L & 1.5 & HPHT $-230^{\circ} \mathrm{F}$ \\
\hline 6 & Conqor 404+ OS1L & 0.5 & HPHT $-230^{\circ} \mathrm{F}$ \\
\hline 8 & Conqor 404+ OS1L & 1 & HPHT $-230^{\circ} \mathrm{F}$ \\
\hline 9 & Conqor 404+ OS1L & 1.5 & HPHT $-230^{\circ} \mathrm{F}$ \\
\hline
\end{tabular}

Table 3: Different medium used in the research set-up for phase 2.

measured using a high accuracy electronic balance. The purpose of the Initial weights is to determine the loss after all exposure and treatment operation. This will also help us understand how the condition of each set-up affects the corrosion rate. One sample (1/4 of a corrosion ring) was immersed in each of the mediums described in Table 2 [7].

\section{Phase 2}

Solution preparation: Table 3 below shows the solutions prepared for Phase 2 experimentation.

Material preparation: Only the corrosion ring of size 5.5 " is used in this phase. Two corrosion rings were into 4 identical pieces in Texas A\&M University - Qatar machine shop. Reasons for only using this size will be presented in the analysis.

Experiment conduction: Each sample of mud will contain each size of corrosion ring to determine corrosion accumulation and inhibition based on the size and type of corrosion ring. After approximately 100 hours of exposure, all corrosion rings will undergo the same procedures of inspection for the evaluation of the results.

\section{Results and Discussion}

\section{Experiment 1}

The weight of each sample was recorded before being immersed in the corrosion mediums and after their removal and cleaning. Tables 4-6 shows the data collected corresponding to corrosion rings of sizes $3.5^{\prime \prime}, 4.5$ " and 5.5 " respectively.

\section{Experiment 2}

Similarly, the weight of each sample was recorded before and after immersion and removal of each sample from the corrosion media. Tables 4-6 show the data collected corresponding to corrosion rings of sizes 3.5", 4.5" and 5.5" respectively (Tables 7-9).

Experiment 1: From the weight data collected, the weight was estimated using equation (4) and the corrosion rates and inhibitor efficiency were also estimated using equations (5) and (6) of the theory 
Citation: Amani M, Abd AS, Al-Hardan A, Roustazadeh A, Yrac R, et al. (2016) Investigating the Effect of High Pressures and Temperatures on Corrosion Inhibition for Water-Based Drilling Fluids. J Pet Environ Biotechnol 7: 297. doi: 10.4172/2157-7463.1000297

Page 4 of 5

section respectively. The results for corrosion ring sizes 3.5 ", 4.5 " and 5.5" are shown respectively in Tables 10-12.

Two samples of 3.5 " corrosion rings were tested under ambient and HPHT conditions. Only water based mud was presented without any type of inhibition. The corrosion rate was severe in HPHT medium (4.1 lbs/ft 2-year) compared to ambient temperature conditions $(2.2$ $\mathrm{lbs} / \mathrm{ft} 2$-year). However, the corrosion rate was determined to be less

\begin{tabular}{|c|c|c|}
\hline \multicolumn{3}{|c|}{ Corrosion Ring of Size 3.5” } \\
\hline Medium & $\mathbf{W}_{\text {initial }}$ (grams) & $\mathbf{W}_{\text {final }}$ (grams) \\
\hline 1 & 16.962 & 16.320 \\
\hline 4 & 16.050 & 14.832 \\
\hline
\end{tabular}

Table 4: Weight data for corrosion ring $3.5^{\prime \prime}$.

\begin{tabular}{|c|c|c|}
\hline \multicolumn{3}{|c|}{ Corrosion Ring of Size 4.5” } \\
\hline Medium & $\mathbf{W}_{\text {initial }}$ (grams) & $\mathbf{W}_{\text {final }}$ (grams) \\
\hline 2 & 20.099 & 19.325 \\
\hline 5 & 19.482 & 18.211 \\
\hline
\end{tabular}

Table 5: Weight data for corrosion ring 4.5".

\begin{tabular}{|c|c|c|}
\hline \multicolumn{3}{|c|}{ Corrosion Ring of Size 5.5” } \\
\hline Medium & $\mathbf{W}_{\text {initial }}$ (grams) & $\mathbf{W}_{\text {final }}$ (grams) \\
\hline 3 & 57.840 & 56.520 \\
\hline 6 & 61.193 & 59.011 \\
\hline
\end{tabular}

Table 6: Weight data for corrosion ring 5.5".

\begin{tabular}{|c|c|c|}
\hline \multicolumn{3}{|c|}{ Corrosion Ring of Size 5.5" with Concor $\mathbf{4 0 4}$} \\
\hline Medium & $\mathbf{W}_{\text {initial }}$ (grams) & $\mathbf{W}_{\text {final }}$ (grams) \\
\hline 1 & 59.090 & 58.001 \\
\hline 2 & 62.295 & 61.416 \\
\hline 3 & 60.283 & 59.928 \\
\hline
\end{tabular}

Table 7: Weight data for corrosion ring 5.5" with concor 404

\begin{tabular}{|c|c|c|}
\hline \multicolumn{3}{|c|}{ Corrosion Ring of Size 5.5” with OS1-L } \\
\hline Medium & W $_{\text {initial }}$ (grams) & $\mathbf{W}_{\text {final }}$ (grams) \\
\hline 4 & 60.790 & 59.389 \\
\hline 5 & 58.708 & 57.354 \\
\hline 6 & 60.855 & 59.884 \\
\hline
\end{tabular}

Table 8: Weight data for corrosion ring 5.5" with OS1-L.

\begin{tabular}{|c|c|c|}
\hline \multicolumn{3}{|c|}{ Corrosion Ring of Size 5.5” with Concor $\mathbf{4 0 4 + \text { OS1-L }}$} \\
\hline Medium & $\mathbf{W}_{\text {initial }}$ (grams) & $\mathbf{W}_{\text {final }}$ (grams) \\
\hline 7 & 59.735 & 58.382 \\
\hline 8 & 59.151 & 57.98 \\
\hline 9 & 59.819 & 59 \\
\hline
\end{tabular}

Table 9: Weight data for corrosion ring 5.5" with concor 404 + OS1-L.

\begin{tabular}{|c|c|c|c|}
\hline \multicolumn{4}{|c|}{ Corrosion Ring of Size 3.5" } \\
\hline Medium & $\begin{array}{c}\text { Weight loss } \\
\text { (grams) }\end{array}$ & $\begin{array}{c}\text { Exposure Time } \\
\text { (hours) }\end{array}$ & $\begin{array}{c}\text { Corrosion rate } \\
\text { (lbs/ft }{ }^{2} \text {-year) }\end{array}$ \\
\hline 1 & 0.642 & 99.08 & 2.2 \\
\hline 4 & 1.218 & 99.87 & 4.1 \\
\hline
\end{tabular}

Table 10: Corrosion rates for corrosion ring 3.5".

\begin{tabular}{|c|c|c|c|}
\hline \multicolumn{4}{|c|}{ Corrosion Ring of Size 4.5" } \\
\hline Medium & $\begin{array}{c}\text { Weight loss } \\
\text { (grams) }\end{array}$ & $\begin{array}{c}\text { Exposure Time } \\
\text { (hours) }\end{array}$ & $\begin{array}{c}\text { Corrosion rate } \\
\text { (lbs/ft }{ }^{2} \text {-year) }\end{array}$ \\
\hline 2 & 0.774 & 99.08 & 2 \\
\hline 5 & 1.271 & 99.87 & 3.2 \\
\hline
\end{tabular}

Table 11: Corrosion rates for corrosion ring 4.5".

\begin{tabular}{|c|c|c|c|}
\hline \multicolumn{4}{|c|}{ Corrosion Ring of Size 5.5” } \\
\hline Medium & $\begin{array}{c}\text { Weight loss } \\
\text { (grams) }\end{array}$ & $\begin{array}{c}\text { Exposure Time } \\
\text { (hours) }\end{array}$ & $\begin{array}{c}\text { Corrosion rate } \\
\text { (lbs/ft } \text {-year) }^{2}\end{array}$ \\
\hline 3 & 1.32 & 99.08 & 1.8 \\
\hline 6 & 2.182 & 99.87 & 2.9 \\
\hline
\end{tabular}

Table 12: Corrosion rates for corrosion ring 5.5".

\begin{tabular}{|c|c|c|c|c|}
\hline \multicolumn{5}{|c|}{ Corrosion Ring of Size 5.5” with Concor 404 } \\
\hline Medium & $\begin{array}{c}\text { Weight loss } \\
\text { (grams) }\end{array}$ & $\begin{array}{c}\text { Exposure Time } \\
\text { (hours) }\end{array}$ & $\begin{array}{c}\text { Corrosion rate } \\
\text { (lbs/ft'-year) }\end{array}$ & $\begin{array}{c}\text { Inhibitor } \\
\text { Efficiency (\%) }\end{array}$ \\
\hline 1 & 1.089 & 99.9 & 1.5 & 48.2 \\
\hline 2 & 0.879 & 99.78 & 1.2 & 58.6 \\
\hline 3 & 0.355 & 100.67 & 0.5 & 82.7 \\
\hline
\end{tabular}

Table 13: Corrosion rates for corrosion ring of size 5.5" with concor 404 .

\begin{tabular}{|c|c|c|c|c|}
\hline \multicolumn{5}{|c|}{ Corrosion Ring of Size 5.5” with OS1-L } \\
\hline Medium & $\begin{array}{c}\text { Weight loss } \\
\text { (grams) }\end{array}$ & $\begin{array}{c}\text { Exposure Time } \\
\text { (hours) }\end{array}$ & $\begin{array}{c}\text { Corrosion rate } \\
\text { (lbs/ft }{ }^{\text {-year) }}\end{array}$ & $\begin{array}{c}\text { Inhibitor } \\
\text { Efficiency (\%) }\end{array}$ \\
\hline 4 & 1.401 & 100.57 & 1.9 & 34.4 \\
\hline 5 & 1.354 & 100.43 & 1.8 & 37.9 \\
\hline 6 & 0.971 & 100.22 & 1.3 & 55.1 \\
\hline
\end{tabular}

Table 14: Corrosion rates for corrosion ring of size 5.5" with OS1-L.

\begin{tabular}{|c|c|c|c|c|}
\hline \multicolumn{5}{|c|}{ Corrosion Ring of Size 5.5” Concor 404 + OS1-L } \\
\hline Medium & $\begin{array}{c}\text { Weight loss } \\
\text { (grams) }\end{array}$ & $\begin{array}{c}\text { Exposure Time } \\
\text { (hours) }\end{array}$ & $\begin{array}{c}\text { Corrosion rate } \\
\text { (lbs/ft } \text {-year) }^{2}\end{array}$ & $\begin{array}{c}\text { Inhibitor } \\
\text { Efficiency (\%) }\end{array}$ \\
\hline 7 & 1.353 & 100.97 & 1.8 & 37.9 \\
\hline 8 & 1.171 & 100.73 & 1.6 & 44.8 \\
\hline 9 & 0.819 & 100.5 & 1.1 & 62 \\
\hline
\end{tabular}

Table 15: Corrosion rates for corrosion ring of size 5.5" with concor 404+OS1-L.

for larger corrosion ring sizes for both mediums with higher rate in the HPHT medium.

The bargraph below allows us to draw a general conclusion relating corrosion rate with corrosion ring size. It is noticeable that the corrosion rate decreases with bigger size as it gets hard to corrode all the metal for same exposure time. Increasing the temperature will accelerate the corrosion process especially for small ring size (3.5") leading to a high and severe corrosion rate [8].

Experiment 2: Based on experiment 1 results, we assume that the corrosion rate decreases with size but increase with temperature. Thus, in this experiment we focused on the large ring size only under HPHT conditions to test different inhibition treatments while expecting to project the results onto the other sizes. Similar to the calculations done to obtain the results of experiment 1, weight loss, corrosion rate, and inhibition efficiency were obtained for the studied samples. Tables 1315 show the impact of using different inhibitors combinations with different concentration on the corrosion rate (Figure 3).

In this experiment two different inhibitors were used. Inhibiting with concor 404 was the most efficient with increasing efficiency of inhibition up to $82 \%$ for high concentrations. The corrosion rate without inhibition was around $2.9 \mathrm{lbs} / \mathrm{ft} 2$-year; almost 6 times higher than when maximum inhibition is applied. On the other hand, using OS1-L, another type of inhibitor, reduced the corrosion rate to $1.3 \mathrm{lbs} /$ $\mathrm{ft} 2$-year for $1.5 \mathrm{ppb}$ inhibitor concentration. This rate is almost three times higher than the rate when Concor 404 is applied. On the other hand, combining both inhibitor will yield and efficiency of $62 \%$ at maximum inhibitor concentration; a value that lies between Concor 404 and OS1-L efficiencies. A plot of corrosion rate versus different types of inhibitors and concentrations can be found below [9] (Figure 4). 
Citation: Amani M, Abd AS, Al-Hardan A, Roustazadeh A, Yrac R, et al. (2016) Investigating the Effect of High Pressures and Temperatures on Corrosion Inhibition for Water-Based Drilling Fluids. J Pet Environ Biotechnol 7: 297. doi: 10.4172/2157-7463.1000297

Page 5 of 5

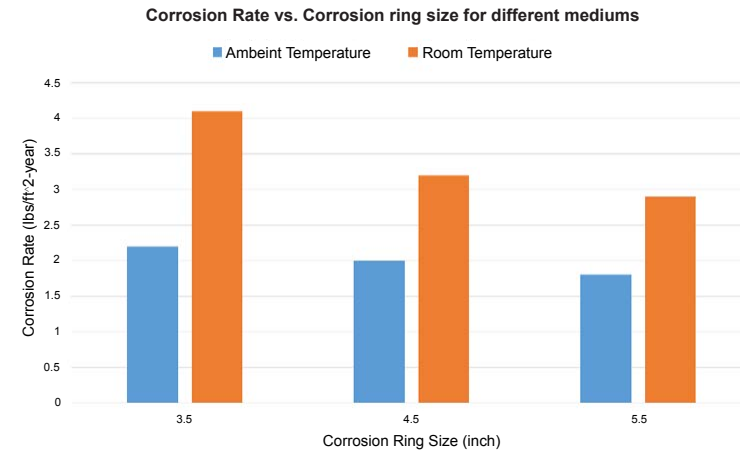

Figure 3: Corrosion rate for different ring sizes in varying temperature.

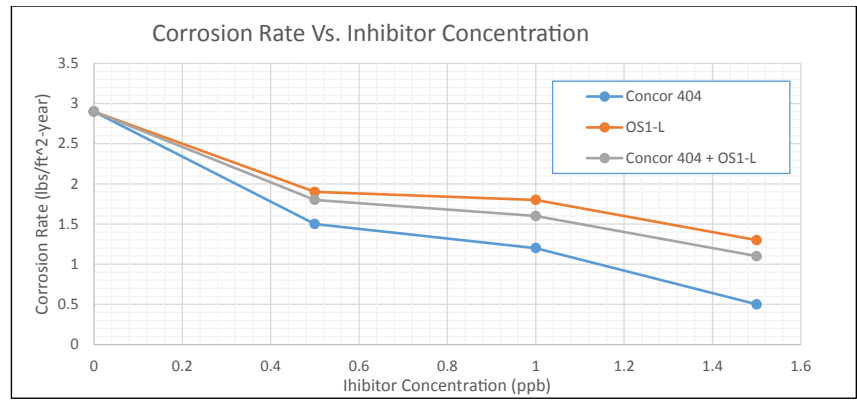

Figure 4: Corrosion rate versus inhibitor concentration.

In order to recommend an inhibition treatment, a balance between cost and efficiency should be achieved. While one of the treatments is the most cost-effective, others could be enhanced to be more costeffective. The goal is to achieve the desired level of service at the least cost. In our case, the price of Concor 404 is estimated to be almost 10 time more than that of OS1-L. The acceptable rate of corrosion can range from 1 to $2 \mathrm{lbs} / \mathrm{ft} \wedge 2$-year while Concor 404 achieves $0.5 \mathrm{bs} / \mathrm{ft} \wedge 2$ year at $1.5 \mathrm{ppb}$ concentration. Having a recommended concentrations of ppb, and combing Concor 404 and OS1-L will yield $1.62 \mathrm{lbs} / \mathrm{ft} \wedge 2$ year corrosion rate which is tolerable. This combination saves money while maintaining integrity of the corroded metal.

\section{Conclusions}

This research focuses on corrosion inhibition treatments for various pressure and temperature conditions. Steel pipes are the most commonly used for oil and gas wells due to their low cost and high performance. During drilling, these steel materials are under very corrosive conditions due to elevated temperatures and pressures as well as exposure to $\mathrm{CO}_{2}$ and $\mathrm{O}_{2}$. Thus, an appropriate inhibitor should be used to prevent corrosion from affecting the integrity of the pipes. Various inhibitors were presented which are used as inhibitive chemicals for steel materials under HPHT conditions.

The following conclusions were made:

a. Efficiency is not the sole factor in treatment selection.

b. Detailed economic analysis including the cost effectiveness is required to successfully manage corrosion.

c. The most efficient and economic treatments amongst the different tested inhibitors was the chemical inhibition through using a mixture of Concor 404 and OS1-L.
Some of the limitations faced throughout this experiment are listed and particularized below:

a. Monitoring the values of thickness and weight periodically while performing the experiment was not possible due to time constraints. Cleaning each sample multiple times and measuring data in consistent time steps is a tedious process. However, if this was done, it would have allowed as to predict a correlation that can relate the corrosion rate with time under certain pressure and temperature conditions.

b. Introducing $\mathrm{H}_{2} \mathrm{~S}$ to the experiment was not allowed in Texas A\&M Labs due to safety concerns. This would have allowed us to simulate downhole conditions of a reservoir in credible criteria.

On other note, some errors were also observed in the experiment mainly due to the interaction with the studied samples which might have altered the results a little bit. These errors, however, won't change the general trend of the observed results.

\section{Recommendations}

The following is recommended: The research should be further developed to study the effects of $\mathrm{H}_{2} \mathrm{~S}$ and $\mathrm{CO}_{2}$ on corrosion rates along with temperature and pressure. A study for the composition of Concor 404 and OS1-L should be done to see why OS1-L is hindering the efficiency of Concor 404 compared to its presence alone.

Different treatment methods other than chemical inhibition should be evaluated and compared for efficiency and cost effectiveness.

\section{Acknowledgment}

"This publication was made possible by a UREP award [UREP No: 17-133-2034] from the Qatar National Research Fund (a member of The Qatar Foundation). The statements made herein are solely the responsibility of the author."

\section{References}

1. Brownlee JK, Flesner KO, Riggs KR, Miglin BP (2005) Selection and qualification of materials for HPHT Wells. Society of Petroleum Engineers.

2. Godwin W, Ogbonna J, Boniface O (2011) Advances in mud design and challenges in HPHT Wells. Society of Petroleum Engineers.

3. Young K, Alexander C, Biel R, Shanks E (2005) Updated design methods for HPHT Equipment. Society of Petroleum Engineers.

4. Shadravan A, Amani M (2012) HPHT 101 - What petroleum engineers and geoscientists should Know about high pressure high temperature wells environment. Journal of Energy Science and Technology 4: 36-60.

5. Al-Tammar JI, Bonis M, Choi HJ, Al-Salim Y (2014) Saudi aramco downhole corrosion/scaling operational experience and challenges in HP/HT Gas Condensate Producers. Society of Petroleum Engineers.

6. Amani M, Hieij DA (2015) Comprehensive review of corrosion inhibition methods in the oil and gas industry. Paper SPE-175337-MS presented at the 2015 SPE Kuwait Oil \& Gas Show and Conference, Kuwait

7. Bland RG, Mullen GA, Gonzalez YN, Harvey FE, Pless ML (2006) HPHT drilling fluid challenges. Society of Petroleum Engineers.

8. Lee J, Shadravan A, Young S (2012) Rheological properties of invert emulsion drilling fluid under extreme HPHT conditions. Presented at the IADC/SPE Drilling Conference and Exhibition, San Diego, California, U.S.A.

9. Weintritt DJ, Hughes RG (1965) Factors involved in high-temperature drilling fluids. Society of Petroleum Engineers. 